\title{
Prediction of the risk of developing diabetes mellitus among Bangladeshi adults by using risk assessment score
}

Akter $\mathrm{N}^{\mathrm{a}}$

\begin{abstract}
Background: Diabetes mellitus (DM) is considered as one of the major health problems worldwide. The rising prevalence of type 2 diabetes mellitus (T2DM) in Bangladesh is primarily attributed to rapid urbanization and associated changes in lifestyle, such as sedentary lifestyle, higher calorie food intake and stressful life. Studies support the utilization of riskassessment scoring systems in quantifying individual's risk for developing T2DM. Thus, a simple risk-assessment scoring system for early screening of T2DM among Bangladeshi adults will be beneficial to identify the high-risk adults and thus taking adequate preventive measures in combating DM.The purpose of the study was to calculate the risk assessment score of developing T2DM within 10 years among Bangladeshi adults.
\end{abstract}

Methods: The cross-sectional observational study was carried out in the outpatient department (OPD) of Medicine, MARKS Medical College \& Hospital, a tertiary care hospital in Dhaka, Bangladesh from February 2018 to July 2018 among randomly sampled 205 adult subjects. Subjects undiagnosed with diabetes mellitus and had previous history of high blood glucose during pregnancy or other health examination (i.e. impaired fasting glucose, impaired glucose tolerance or gestational diabetes mellitus) were included. From a review of literature regarding risk factors of developing DM in Bangladesh, the Finnish Diabetes Risk Score (FINDRISC) system was found to be more useful for the Bangladeshi adults. The Finnish Diabetes Risk Score (FINDRISC) questionnaire was used to collect the data including demographic characteristics and different risk factors and to calculate total risk score for predicting the risk of developing T2DM within 10 years.

Results: Among 205 subjects, male and female were $57.1 \%$ and $42.9 \%$ respectively. The Mean ( \pm SD) age of the study subjects was 37.64 1.07 years. In this study, both non-modifiable and modifiable risk factors showed statistically significant association with the FINDRISC among Bangladeshi adults $(p<0.05)$. There was a significant association among FINDRISC with history of previous high blood glucose, and treated hypertensive Bangladeshi adults.33.65\% of the Bangladeshi adults had slightly elevated diabetes risk score (DRS). This study predicts that $17.55 \%$ of the Bangladeshi adults may have moderate to high risk to develop T2DM within the consecutive 10 years.

Conclusion: This study provides a simple, feasible, non-invasive and convenient screening FINDRISC tool that identifies individuals at risk of having T2DM. People with high risk of DM should be referred for early intervention and changes to a healthy lifestyle and primary prevention to prevent or delay the onset of T2DM.

Keywords: FINDRISC, Risk Assessment Score, Type 2 Diabetes Mellitus.

(BIRDEM Med J 2020; 10(1): 40-47)

\section{Introduction}

Diabetes is now recognized as a major chronic public health problem throughout the world and affecting a large number of people in a wide range of ethnic and

\section{Author information}

1. Dr. Nazma Akter, Assistant Professor (Endocrinology \& Metabolism), Department of Medicine, MARKS Medical College \& Hospital, Dhaka,Bangladesh.

Address of correspondence: Dr. Nazma Akter, Assistant Professor (Endocrinology \& Metabolism), Department of Medicine, MARKS Medical College \& Hospital, Dhaka, Bangladesh. Email: nazma aktar_endo@yahoo.com

Receive: July 8, 2019

Accepted: October 31, 2019 economic levels in both developed and developing countries. However, it is estimated that the developing countries will bear the brunt of this epidemic in the $21 \mathrm{st}$ century, with $80 \%$ of all new cases of diabetes are expected to appear in the developing countries by $2025^{1}$ including South Asian countries like Bangladesh. ${ }^{2}$ The International Diabetes Federation (IDF) estimates, Bangladesh has nearly 8.4 million of diabetic patients which is expected to reach to 16.8 million by $2030 .{ }^{3} \mathrm{In}$ Bangladesh most of the patients are type 2 diabetics and the risk of developing type 2 diabetes mellitus 
(T2DM) is determined by some modifiable factors related to rapid urban growth and changing lifestyle (i.e. obesity, sedentary lifestyle, diet, smoking, physical and emotional stress) and non-modifiable factors (i.e. family history of diabetes, age, race/ethnicity). ${ }^{4,5}$ The rising prevalence of T2DM in Bangladesh is primarily attributed to rapid urbanization and associated changes in lifestyle, such as sedentary lifestyle, higher calorie food intake and stressful life. ${ }^{5-7}$ Prevention of diabetes is important because it is costly both in human and monetary matters. ${ }^{8}$ Awareness of risk factors is a prerequisite to prevent diabetes among general population and also in high-risk groups, such as impaired fasting glucose (IFG) and impaired glucose tolerance (IGT). ${ }^{9-11}$ The benefits of early detection and intervention on improved health outcomes and reduced morbidity associated with T2DM are shown in many studies. ${ }^{13,14}$

As the prevalence of DM among Bangladeshi adults rises prediction of new cases of T2DM in Bangladesh requires early identification and screening. Studies also support the utilization of risk-assessment scoring systems in quantifying individual's risk for developing T2DM. ${ }^{15}$ Thus, using a simple risk-assessment scoring system for early screening of T2DM among Bangladeshi adults will be beneficial to identify the high-risk adults and thus taking adequate preventive measures in combating diabetes. The purpose of the study was to calculate the risk assessment score of developing T2DM within 10 years among Bangladeshi adults.

\section{Methods}

The cross-sectional observational study was carried out in the outpatient department (OPD) of Medicine, MARKS Medical College \& Hospital, a tertiary care hospital in Dhaka, Bangladesh from February 2018 to July 2018 among randomly sampled 205 adult Bangladeshi male and female subjects. Subjects undiagnosed with diabetes mellitus and had previous history of high blood glucose during pregnancy or other health examination (i.e. impaired fasting glucose, impaired glucose tolerance or gestational diabetes mellitus) were included. Individuals with a apparent communicative, cognitive impairment or physical disability were excluded from the study. With written informed consent, the Finnish Diabetes Risk Score (FINDRISC) questionnaire was used to collect the data including demographic characteristics and different risk factors and to calculate total risk score for predictors the risk of developing T2DM within 10 years.

\section{Methods of calculation of FINDRISC}

Various risk factors of T2DM were reviewed from the literature like sex, age at diagnosis of diabetes, ethnicity, family history of diabetes, diet and exercise, smoking and alcohol usage, hypertension, hyperlipidaemia, body mass index (BMI), weight, waist circumference (WC), gestational diabetes, macrosomia and polycystic ovarian syndrome. ${ }^{17}$ Various risk-assessment scoring systems were reviewed like American Diabetes Association, ${ }^{19}$ Rotterdam, ${ }^{16}$ Cambridge, ${ }^{14}$ Finnish, ${ }^{20}$ Danish, ${ }^{21}$ Indian, ${ }^{22}$ Thai, ${ }^{23}$ Omani, ${ }^{24}$ Kuwaiti, ${ }^{12}$ Australian T2DM risk-assessment tool and Trinidad Risk Assessment Questionnaire-5 (TRAQ-5). ${ }^{25}$ The Finnish Diabetes Risk Score (FINDRISC) developed in 2001 and tested for validity and reliability on Finnish population and in different countries. ${ }^{20,26-30}$ In Bangladesh, still we do not have any diabetes risk assessment scoring system. After review of literature regarding risk factors of developing diabetesin Bangladesh, we also reviewed some other well validated risk assessment scoring systems for diabetes of different countries. We found the risk assessment tools of the Finnish Diabetes Risk Score (FINDRISC) ${ }^{20}$ to calculate risk score was more useful for the Bangladeshi adults. The FINDRISC had 8 risk factors correlating with the risk of developing T2DM and was used as a prognostic screening tool to detect a diabetes risk in a 10-year period based on age, family history, WC, BMI, physical activity, vegetable/fruit diet, past history of hypertension and blood glucose. It demonstrates the probability of developing T2DM within 10 years and the risk score is categorized as $<7$ : low (estimated 1 in 100 will develop DM), 7-11: slightly elevated (estimated 1 in 25 will develop DM), 12-14: moderate (estimated 1 in 6 will develop DM), 15-20: high (estimated 1 in 3 will develop DM) and $>20$ : very high (estimated 1 in 2 will develop DM). Hence, the FINDRISC tool was found to be appropriate for the purpose of this study.

\section{Component of FINDRISC tool}

Anthropometric measurements of height and weight were measured by a reliable height scale and weighing scale, respectively. Random blood glucose was measured using laboratory blood glucose test. ${ }^{21,31} \mathrm{BMI}$ 
(weight in kilograms/square of height in meters $\left(\mathrm{kg} / \mathrm{m}^{2}\right.$ ) was categorized as underweight $\left(<18.5 \mathrm{~kg} / \mathrm{m}^{2}\right)$, normal (BMI: $18-25 \mathrm{~kg} / \mathrm{m}^{2}$ ), overweight (BMI: $25-30 \mathrm{~kg} / \mathrm{m}^{2}$ ) and obese (BMI: $\geq 30 \mathrm{~kg} / \mathrm{m}^{2}$ ). Hypertension was defined as a systolic blood pressure $\geq 140 \mathrm{mmHg}$ and/or diastolic blood pressure $\geq 90 \mathrm{mmHg}$, or in case of use of anti-hypertensive medications ${ }^{19}$ was measured by a manual sphygmomanometer in standard conditions (measured 2 times after a 5 -min rest between each measurement). ${ }^{32} \mathrm{WC} \geq 90 \mathrm{~cm}$ for males and $\geq 80 \mathrm{~cm}$ (35 inches) for females was considered as a risk factor for $\mathrm{DM},{ }^{33}$ and it was measured in a horizontal plane, midway between the inferior margin of the ribs and the superior border of the iliac crest using a reliable measuring inch tape.

\section{Statistical analysis}

Data were analyzed with Statistical Package for Social Science (SPSS) software version 16. The means and standard deviations were used to describe continuous data. For categorical data, frequencies and percentages were estimated. Among the basic characteristics of the study subjects, the continuous variables were compared with each other using the Student's t-test. Categorical variables were compared with each other using the chi- square test. $\mathrm{P}$ value $<0.05$ was considered as significant.

\section{Results}

Demographic and clinical characteristics

A total of 205 subjects were included. Among them male and female were $57.1 \%$ and $42.9 \%$ respectively. The mean $( \pm \mathrm{SD})$ age of the study subjects was $37.64 \pm 1.07$ years. Maximum age was 71 years and minimum was 21 years. The mean $( \pm \mathrm{SD})$ age of the male and female were $39.82 \pm 1.16$ and $34.73 \pm 8.68$ years respectively $(\mathrm{p}<0.05)$. The mean $( \pm \mathrm{SD})$ height(meter)and weight $(\mathrm{kg})$ were higher in male subjects than female $(1.65 \pm 6.11$ vs. $1.57 \pm 1.28$ and $68.45 \pm 1.10$ vs. $59.07 \pm 1.09$ respectively); $(\mathrm{p}<0.05)$. Average $\mathrm{BMI}\left(\mathrm{kg} / \mathrm{m}^{2}\right)$ was 24.75 \pm 3.59 in male subjects and $24.37 \pm 4.15$ (Mean \pm SD) in female subjects; $(p=0.48)$. And average Waist Circumference $(\mathrm{cm})$ was $90.75 \pm 8.68$ in male and $84.61 \pm 12.17$ ( Mean \pm SD) in female $(\mathrm{p}<0.05)$ The Mean $( \pm \mathrm{SD})$ Blood Pressure $(\mathrm{mm}$ of $\mathrm{Hg})$ of the study subjects were SBP: $116.32 \pm 1.22$ vs. $111.48 \pm 9.77$ and DBP: $78.75 \pm 8.98$ vs. $73.75 \pm 8.34$ in male and female respectively. Random blood sugar $(\mathrm{mmol} / \mathrm{L})$ was $6.17 \pm 1.91$ in male and $5.80 \pm 1.77$ in female ( Mean $\pm \mathrm{SD}$ ). (Table I)

Table I Comparison of demographic, clinical, biochemical \& FINDRISC of developing type 2 diabetes between male \& female subjects $(\mathrm{n}=205)$.

\begin{tabular}{lccc}
\hline Variables & Male & Female & p \\
& Mean \pm SD & Mean \pm SD & value \\
\hline Age $($ Yrs $)$ & $39.82 \pm 1.16$ & $34.73 \pm 8.68$ & 0.001 \\
Height $(\mathrm{m})$ & $1.65 \pm 6.11$ & $1.57 \pm 1.28$ & $<0.001$ \\
Weight $(\mathrm{kg})$ & $68.45 \pm 1.10$ & $59.07 \pm 1.09$ & $<0.001$ \\
BMI $\left(\mathrm{kg} / \mathrm{m}^{2}\right)$ & $24.75 \pm 3.59$ & $24.37 \pm 4.15$ & 0.488 \\
WC $(\mathrm{cm})$ & $90.75 \pm 8.68$ & $84.61 \pm 12.17$ & $<0.001$ \\
SBP $(\mathrm{mm}$ of Hg) & $116.32 \pm 1.22$ & $111.48 \pm 9.77$ & 0.003 \\
DBP (mm of Hg) & $78.75 \pm 8.98$ & $73.75 \pm 8.34$ & 0.016 \\
RBS (mmol/L) & $6.17 \pm 1.91$ & $5.80 \pm 1.77$ & 0.162 \\
FINDRISC( 10 -year Risk Scores) & $6.92 \pm 4.48$ & $7.40 \pm 5.25$ & 0.476 \\
\hline
\end{tabular}

BMI: Body mass index; WC: Waist circumference;SBP: Systolic Blood Pressure; DBP: Diastolic Blood Pressure;RBS: Random Blood Sugar; FINDRISC: Finnish Diabetes Risk Score. 
Some of the adults had a family history (parents, grandparents, aunts, uncles; $52.7 \%)$ of DM $(\mathrm{p}<0.05)$. A total of $42.49 \%$ of the adults had no daily physical activity and low intake of vegetables, fruits or berries $(38.0 \%) ;(p<0.05)$. Some of the adults had high BMI (34.1\% were overweight and $8.8 \%$ were obese); $(\mathrm{p}<0.05)$ and high WC $(22.4 \%$ in male and $30.3 \%$ in female); $(p<0.05)$. A total of $10.2 \%$ of the adults had hypertension and were on anti-hypertensive medications, and $12.2 \%$ had previous history of high blood glucose during pregnancy or during other health examination (i.e. impaired fasting glucose, impaired glucose tolerance or gestational diabetes mellitus) $(\mathrm{p}<0.05)$ [Table II \& Table III].

\section{Risk assessment score (FINDRISC) among Bangladeshi adults}

The FINDRISC predicted 10-year risk of developing T2DM was more in female subjects than male $(p=0.47)$ ). Among subjects, the mean (Mean \pm SD) FINDRISC were $7.40 \pm 5.25$ vs. $6.92 \pm 4.48$ (female vs. male). (Table 1)

A total of $33.65 \%$ of the Bangladeshi adults had slightly elevated dia-betes risk score (DRS). Among them, 62.31\% were male and $37.68 \%$ were female. No one had very high risk score. While $10.73 \%$ had moderate DRS (Male vs. Female were $45.45 \%$ vs. $54.54 \%$ ) and $6.82 \%$ had high DRS (among them 50\% were male \& 50\% were female); $(p=0.51)$. This predicts that $17.55 \%$ of the Bangladeshi adults may have moderate to high risk to develop T2DM within the consecutive 10 years, if no primary preventive measures are taken to curb it (Figure $1 \&$ Figure2).

Table II Prevalence of risk assessment factors for prediction of FINDRISC of developing type 2 diabetes among Bangladeshi subjects $(n=205)$.

\begin{tabular}{|c|c|c|c|}
\hline \multicolumn{2}{|l|}{ Risk Assessment Factors of FINDRISC } & Frequency & Percentage \\
\hline \multirow[t]{4}{*}{ Age (years) } & $<45$ Years & 149 & 72.7 \\
\hline & 45-54 Years & 44 & 21.5 \\
\hline & 55-64 Years & 10 & 4.9 \\
\hline & $>64$ Years & 2 & 1.0 \\
\hline \multirow[t]{3}{*}{ Family history of diabetes mellitus } & No & 97 & 47.3 \\
\hline & $\begin{array}{l}\text { Grand Parent, aunt, uncle, or } \\
\text { first cousin }\end{array}$ & 32 & 15.6 \\
\hline & Parent, sibling, children & 76 & 37.1 \\
\hline \multirow[t]{3}{*}{ BMI $\left(\mathrm{kg} / \mathrm{m}^{2}\right)$} & Normal: Lower than $25 \mathrm{~kg} / \mathrm{m}^{2}$ & 117 & 57.1 \\
\hline & Over weight: $25-30 \mathrm{~kg} / \mathrm{m}^{2}$ & 70 & 34.1 \\
\hline & Obese: Higher than $30 \mathrm{~kg} / \mathrm{m}^{2}$ & 18 & 8.8 \\
\hline \multirow[t]{3}{*}{ Waist circumference $(\mathrm{cm}) \quad$ Male } & Less than $94 \mathrm{~cm}$ & 69 & 33.7 \\
\hline & $94-102 \mathrm{~cm}$ & 43 & 21.0 \\
\hline & More than $102 \mathrm{~cm}$ & 5 & 2.4 \\
\hline \multirow[t]{3}{*}{ Female } & Less than $80 \mathrm{~cm}$ & 26 & 12.7 \\
\hline & $80-88 \mathrm{~cm}$ & 26 & 12.7 \\
\hline & More than $88 \mathrm{~cm}$ & 36 & 17.6 \\
\hline \multirow[t]{2}{*}{ Physical activity daily $\mathbf{3 0}$ min } & Yes & 118 & 57.6 \\
\hline & No & 87 & 42.4 \\
\hline \multirow[t]{2}{*}{ Vegetables, fruit or berry consumption } & Every day & 127 & 62.0 \\
\hline & Not every day & 78 & 38.0 \\
\hline \multirow{2}{*}{$\begin{array}{l}\text { History of hypertension with or without } \\
\text { anti-hypertensive }\end{array}$} & No & 184 & 89.8 \\
\hline & Yes & 21 & 10.2 \\
\hline \multirow{2}{*}{$\begin{array}{l}\text { History of previous high blood glucose } \\
\text { (i.e. IFG, IGT, GDM) }\end{array}$} & No & 180 & 87.8 \\
\hline & Yes & 25 & 12.2 \\
\hline \multirow[t]{2}{*}{ Gender } & Male & 117 & 57.1 \\
\hline & Female & 88 & 42.9 \\
\hline
\end{tabular}

BMI: body Mass Index; IFG: Impaired Fasting Glucose; IGT: Impaired Glucose Tolerance; GDM: Gestational Diabetes Mellitus; FINDRISC: Finnish Diabetes Risk Score. 
Table III Association of risk factors of Finish Diabetes Risk Score among Bangladeshi adults. ( $N=205)$

\begin{tabular}{|c|c|c|c|c|c|}
\hline \multicolumn{3}{|l|}{ Risk Assessment Factors ofFINDRISC } & $\lambda$ value & df & $\mathrm{p}$ \\
\hline \multicolumn{2}{|l|}{ Age (years) } & $\begin{array}{l}<45 \text { Years } \\
45-54 \text { Years } \\
55-64 \text { Years } \\
>64 \text { Years }\end{array}$ & 37.768 & 9 & $<0.001$ \\
\hline \multicolumn{2}{|l|}{ Family history of Diabetes Mellitus } & $\begin{array}{l}\text { No } \\
\text { Grand Parent, aunt, uncle, } \\
\text { or first cousin Parent, } \\
\text { sibling, children }\end{array}$ & 63.489 & 6 & $<0.001$ \\
\hline \multicolumn{2}{|l|}{ BMI $\left(\mathrm{kg} / \mathrm{m}^{2}\right)$} & $\begin{array}{l}\text { Normal: Lower } \\
\text { than } 25 \mathrm{~kg} / \mathrm{m}^{2} \\
\text { Over weight: } \\
25-30 \mathrm{~kg} / \mathrm{m}^{2} \\
\text { Obese: Higher than } \\
30 \mathrm{~kg} / \mathrm{m}^{2}\end{array}$ & 33.818 & 6 & $<0.001$ \\
\hline \multirow[t]{2}{*}{ Waist circumference $(\mathrm{cm})$} & Male & $\begin{array}{l}\text { Less than } 94 \mathrm{~cm} \\
94-102 \mathrm{~cm} \\
\text { More than } 102 \mathrm{~cm}\end{array}$ & 22.861 & 9 & 0.007 \\
\hline & Female & $\begin{array}{l}\text { Less than } 80 \mathrm{~cm} \\
80-88 \mathrm{~cm} \\
\text { More than } 88 \mathrm{~cm}\end{array}$ & 19.66 & 9 & 0.020 \\
\hline Physical activity daily $30 \mathrm{~min}$ & $\begin{array}{l}\text { Yes } \\
\text { No }\end{array}$ & 21.935 & 3 & $<0.001$ & \\
\hline \multicolumn{2}{|l|}{ Vegetables, fruit or berry consumption } & $\begin{array}{l}\text { Every day } \\
\text { Not every day }\end{array}$ & 10.597 & 3 & 0.014 \\
\hline \multicolumn{2}{|l|}{$\begin{array}{l}\text { History of hypertensive with or } \\
\text { without anti-hypertensive }\end{array}$} & $\begin{array}{l}\text { No } \\
\text { Yes }\end{array}$ & 41.502 & 3 & $<0.001$ \\
\hline \multicolumn{2}{|l|}{$\begin{array}{l}\text { History of previous high blood glucose } \\
\text { (i.e. IFG, IGT, GDM) }\end{array}$} & $\begin{array}{l}\text { No } \\
\text { Yes }\end{array}$ & 1.073 & 3 & $<0.001$ \\
\hline
\end{tabular}

BMI: Body mass index; FBG: fasting blood glucose; IFG: Impaired Fasting Glucose; IGT: Impaired Glucose; FINDRISC: Finish Diabetes Risk Score. Tolerance; GDM: Gestational Diabetes Mellitus; Pearson chi-square $=$ ë value; df: degree of freedom; $\mathrm{p}<0.05=$ significant.

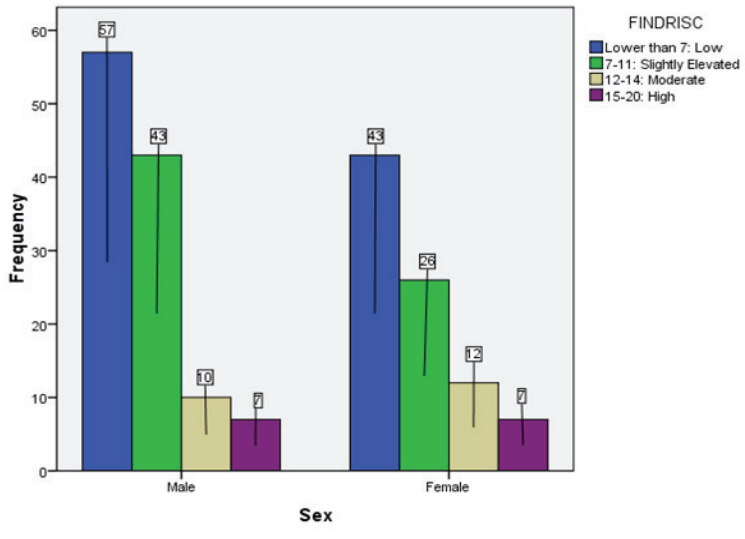

Figure 1 Risk assessment scoring system (FINDRISE) among Bangladeshi adult $(\mathrm{n}=205)$

NB: FINDRISC: Finnish Diabetes Risk Score.

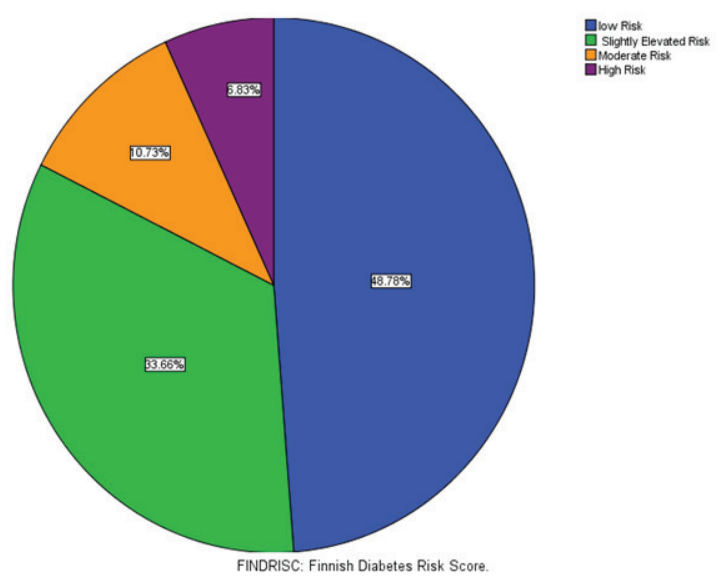

Figure 2 Percentage of total risk score (findrisc) among Bangladeshi adult ( $\mathrm{n}=205)$ 


\section{Discussion}

With the rapid transition in economic development, industrialization and globalization have lead to lifestyle changes and increase in life expectancy in most areas of the world. This increase in cultural and lifestyle changes, including unhealthy dietary habits and decrease in physical activity, has been accompanied by an increase in the prevalence of non-communicable (chronic) diseases, including DM. ${ }^{34}$ The preventable lifestyle-related risk factors of T2DM are overweight, abdominal obesity and sedentary life style with high saturated fat, refined carbohydrate, total energy and low dietary fiber intake. ${ }^{35}$ The increasing prevalence of diabetes and its complications in Bangladesh would pose a real threat to existing health services. Assessment of the risk score of diabetes can assist in its early detection, prevention and reduce its incidence.

FINDRISC is a useful tool for identifying people with asymptomatic DM who might not seek early or regular evaluation, thus facilitating intervention early in the disease course. Early detection leads to a better quality of life, reduced morbidity, premature mortality and ultimately a reduction in associated health care and wider economic costs. Adults with slightly elevated highrisk assessment score, regardless of their blood glucose status, are suitable candidates for lifestyle modification. The health care professionals can empower the patients in the moderate-high-risk group to be self-motivated with life style modifications like increasing physical activity, maintaining ideal body weight and periodic health checks, including blood glucose and blood pressure. This should prompt high-risk adults with knowledge acquisition on prevention, early detection, treatment and disability limitation in prevention of DM leading to quality care. ${ }^{36,37} \mathrm{~A}$ high dietary fiber and increase in vegetable consumption, low-moderate total calorie, reduced fat, low glycaemic index foods and low polyunsaturated fat will reduce the susceptibility to DM. ${ }^{38}$ At least 30 min of moderate physical activity with variable emphasis on high-intensity and resistance training exercise (e.g. brisk walking, swimming, cycling, dancing) on all or most days of the week are recommended. Regular walking for at least 30 min per day reduces diabetes risk by 35\%" $40 \% .{ }^{39}$ This has been proven to effectively prevent and delay the development of DM among young adults. ${ }^{40}$

In this study, the non-modifiable risk factors i.e. age, positive family history of diabetes, history of hypertension or blood glucose were the sig-nificant independent risk factors for predicting T2DM. However, BMI, WC, physical activity and dietary intake were the significant modifiable risk factors. Both non-modifiable and modifiable risk factors were statistically significant with the FINDRISC among Bangladeshi adults $(p<0.05)$. Hypertension is a major risk factor for atherosclerosis and diabetes. ${ }^{41} \mathrm{An}$ increase in blood pressure is significantly associated with diabetes, particularly among urban-dwellers than rural areas. ${ }^{42}$ There was a significant association of FINDRISC with history of hypertension and previous history of high blood glucose among the Bangladeshi adults.

In Bangladesh, prevalence of diabetes in adults is $6.9 \% 43$, with significant predictors like age, hypertension, obesity /WC/BMI and family history. ${ }^{12}$ In this study among subjects, $33.65 \%$ of the Bangladeshi adults had slightly elevated diabetes risk score (DRS). $17.55 \%$ had high or moderately elevated FINDRISC. This predicts that $33.65 \%$ of the Bangladeshi adults have slightly elevated risk and $17.55 \%$ of the adults have moderate to high risk to develop T2DM within the consecutive 10 years, if no primary preventive measures are taken to curb it. This assessment will help to increase awareness and motivate the public about the importance of modifiable anthropometric risk factors regarding T2DM. ${ }^{44}$

\section{Conclusion}

This study provides a simple, feasible, non-invasive and convenient screening FINDRISC tool that identifies individuals at risk of having T2DM. People with high risk of DM should be referred for early intervention and changes to a healthy lifestyle and primary prevention to prevent or delay the onset of T2DM. From public health perspective, there is a critical need for innovative target oriented prevention programs for people who are high-risk individuals to adopt a healthy lifestyle, undergo routine medical check-ups and be an active player in the prevention of diabetes.

\section{Limitations}

This study is limited by the cross-sectional design and is not causal or effect study or measure of temporal changes. Validation of the risk assessment with a large sample size in different populations would have enhanced the generalizability of the results.

Conflict of interest: Nothing to declare. 


\section{References}

1. World Health Organization: World Diabetes: A News Letter. Geneva, Switzerland: WHO; 2003:3-6.

2. Wild S, Roglic G, Green A, Sicree R, King H. Global prevalence of diabetes: estimates for the year 2000 and projections for 2030. Diabetes Care 2004;27:1047-1053.

3. International Diabetes Federation: IDF Diabetes Atlas. 5th edition. Brussels, Belgium: International Diabetes Federation; 2011.

4. Risk factors. 2014. http://www.idf.org/about-diabetes/riskfactors.

5. Hussain A, Claussen B, Ramachandran A, Williams R: Prevention of type 2 diabetes: a review. Diabetes Res ClinPract 2006; 76:317-326.

6. Knowler WC, Barrett-Connor E, Fowler SE, Hamman RF, Lachin JM, Walker EA, Nathan DM: Reduction in the incidence of type 2 diabetes with lifestyle intervention or metformin. N Engl J Med 2002; 346:393-403.

7. Naomi H, Susan MM, Elizabeth H, Christine C, Simone B, Naomi C, Michael K. A risk factor profile for pre-diabetes: biochemical, behavioral, psychosocial and cultural factors. Electron J ApplPsychol 2007; 3(2):14-26.

8. Ambigapathy R, Ambigapathy S, Ling HM. A knowledge, attitude and practice (KAP) study of diabetes mellitus among patients attending KlinikKesihatan Seri Manjung. NCD Malays 2003; 2(2):6-15.

9. Kreuter MW, Strecher VJ. Changing inaccurate perceptions of health risk: results from a randomized trial. Health Psychol 1995; 14:56-63.

10. Struewing JP, Lerman C, Kase RG, Giamberresi TR, Tucker MA.Anticipated uptake and impact of genetic testing in hereditary breast and ovarian cancer families.CancerEpidemiol Biomarkers Prev 1995; 4:169-173.

11. Marteau TM, Kidd J, Cook R, Michie S, Johnston M, Slack J. Perceived risk not actual risk predicts uptake of amniocentesis. Br J ObstetGynaecol 1991; 98:282-286.

12. National Institute for Health and Care Excellence. Preventing type 2 diabetes: risk identification and interventions for indi-viduals at high risk. NICE public health guidance 38 2012, London.

13. Weinstein ND: What does it mean to understand a risk? evaluating risk comprehension. J Natl Cancer InstMonogr 1999; 25:15-20

14. Griffin SJ, Little PS, Hales CN, Kinmonth AL, Wareham NJ. Diabetes risk score: towards earlier detection of type 2 diabetes in general practice. Diabetes Metab Res Rev2000; 16(3): 164 171 .

15. Wilson PW, D'Agostino RB, Levy D,Belanger AM, Silbershatz H, Kannel WB.Prediction of cor-onary heart disease using risk factor categories.Circulation1998; 97(18): 1837-1847.
16. Baan CA, Ruige JB, Stolk RP,Witteman JC, Dekker JM, Heine RJ, Feskens EJ.Performance of a predic-tive model to identify undiagnosed diabetes in a health care setting.Diabetes Care 1999; 22(2): 213-219.

17. Franciosi M, De Berardis G, Rossi MC, Sacco M, Belfiglio M, Pellegrini F, Tognoni G, Valentini M, NicolucciA.Use of the dia-betes risk score for opportunistic screening of undiagnosed diabetes and impaired glucose tolerance: the IGLOO (Impaired Glucose Tolerance and Long-Term Outcomes Observational) study. Diabetes Care2005; 28(5): 1187-1194.

18. Van Der Ven NC, Weinger K, Yi J, Pouwer F, Adèr H, Van Der Ploeg HM, SnoekFJ.The confidence in diabetes self-care scale: psychometric properties of a new mea-sure of diabetesspecific self-efficacy in Dutch and US patients with type 1 diabetes. Diabetes Care2003; 26(3): 713-718.

19. Herman WH, Smith PJ, Thompson TJ, Engelgau M, Aubert R. A new and simple questionnaire to identify people at increased risk for undiag-nosed diabetes.Diabetes Care1995; 18(3): 382-387.

20. Lindstrom $\mathrm{J}$ and Tuomilehto J. The diabetes risk score: a prac-tical tool to predict type 2 diabetes risk. Diabetes Care 2003; 26: 725-731.

21. Glumer C, Jorgensen T and Borch-Johnsen K. Targeted screening for undiagnosed diabetes reduces the number of diagnostic tests. Inter99(8). Diabet Med 2004; 21: 874-880.

22. Mohan V, Deepa R, Deepa M, Somannavar S, Datta M. A simplified Indian Dia-betes Risk Score for screening for undiagnosed diabetic sub-jects. J Assoc of Physicians India 2005; 53: 759-763.

23. Aekplakorn W, Bunnag P, Woodward M, Sritara P, Cheepudomwit S, Yamwong S, Yipintsoi T, Rajatanavin R.A risk score for predicting incident diabetes in the Thai Population. Diabe-tes Care 2006; 29: 1872-1877.

24. Al-LawatiJA,Tuomilehto J. Diabetes risk score in Oman: a tool to identify prevalent type 2 diabetes among Arabs of the Middle East. Diabetes Res ClinPract2007; 77(3): 438-444.

25. Latchan Z, Seereeram R, Kamalodeen A, Sanchez S, Deonarine U, Sinanan R, Mungrue K. TRAQ-D (Trinidad Risk Assessment Questionnaire for Type 2 Diabe-tes Mellitus): a cheap, reliable, non-invasive screening tool for diabetes. Br J Diabetes Vasc Dis 2010; 10: 187-192.

26. Saaristo T, Peltonen M, Keinänen-Kiukaanniemi S,Vanhala M, Saltevo J, Niskanen L, Oksa H, Korpi-Hyövälti E, Tuomilehto J. type 2 diabetes prevention programme in Finland: FIN-D2D. Int J Circumpolar Health 2007; 66(2): 101-112.

27. Schwarz PE, Lindstrom J, Kissimova-Scarbeck K,Szybinski Z, Barengo NC, Peltonen M, Tuomilehto J. DE-PLAN project. The European perspective of type 2 diabetes prevention: diabetes in Europe - prevention using lifestyle, physical activity and nutritional intervention (DE-PLAN) project. ExpClinEndocrinolDiab2008; 116(3): 167-172. 
28. Schwarz PEH, Li J, Reimann M, Schutte AE, Bergmann A, Hanefeld M, Bornstein SR, Schulze J, Tuomilehto J, LindströmJ.The Finnish Diabetes Risk Score is associated with insulin resistance and progres-sion towards type 2 diabetes. J ClinEndocrinolMetab2009; 94: 920-926.

29. Bergmann A, Li J, Wang L, Schulze J, Bornstein SR, Schwarz PE. A simplified Finnish dia-betes risk score to predict type 2 diabetes risk and disease evolution in a German population. HormMetab Res 2007; 39(9): 677-682.

30. Allsema M, Feskens EJ, Bakker SJ, Miguel MG, Núria IJ, Ramon E, Francisco B, Jordi SS. Finnish question-naire reasonably good predictor of the incidence of diabetes in The Netherlands. Ned TijdschrGeneeskd2008; 152(44): 24182424.

31. World Health Organization (WHO). Definition, diagnosis and classification of diabetes mellitus and its complications. Part 1: diagnosis and classification of diabetes mellitus. Report of a WHO Consultation. Report no. WHO/NCD/NCS/99.2, 1999. Geneva: WHO.

32. Smith Liz. New AHA recommendations for blood pressure measurement: American Heart Association Practice Guide-lines. Am Fam Physician 2005; 72(7): 1391-1398.

33. Alberti G, ZimmetP, Shaw J. Metabolic syndrome - a new worldwide definition. A consensus statement from the International Diabetes Federation.Diabet Met 2006; 23: 469480 .

34. International Diabetes Federation. Diabetes Atlas. 3rd ed., 2006, https://www.idf.org/sites/default/files/Diabetes $\%$ 20Atlas\%203rd\%20edition.pdf

35. Al-Moosa S, Allin S, Jemiai N, Jawad AL, Elias M. Diabetes and urbaniza-tion in the Omani population: an analysis of national survey data. Popul Health Metr2006; 4: 5-12.
36. International Diabetes Federation. Global guideline for type 2 diabetes, 2010, http://www.idf.org/webdata/docs/ IDF\%20GGT2D.pdf

37. Expert Panel on Detection, Evaluation, and Treatment of High Blood Cholesterol in Adults. Executive summary of the third report of the National Cholesterol Education Program (NCEP) Expert Panel on Detection, Evaluation, and Treatment of High Blood Cholesterol in Adults (Adult Treatment Panel III). JAMA 2001; 285(19): 2486-2497.

38. Alyaarubi S. Diabetes care in Oman: obstacles and solutions. Sultan QaboosUniv Med J 2011; 11(3): 343-348.

39. Chien KL, Hsu HC, Su TC, Chen MF, Lee YT, Hu FB. Fasting and post challenge hyperglycemia and risk of cardiovascular disease in Chinese: the Chin-Shan Community Cardiovascular Cohort study. Am Heart J 2008; 156(5): 996-1002.

40. Haffner S. Diabetes and the metabolic syndrome - when is it best to intervene to prevent? AtherosclerSuppl2006; 7: 3-10.

41. Al-Riyami A and Afifi M. Distribution and correlates of total impaired fasting glucose in Oman. East Mediterr Health J 2003; 9: 377-389.

42. Mainous III AG, Diaz VA, Everett CJ. Assessing risk for development of diabetes in young adults.AnnFam Med 2007; 5: 425-429.

43. Garfield S, Malozowski S, Chin M, Venkat Narayan K, Glasgow R, Green Hiss R, Krumholz H: Considerations for diabetes translation research in real-world settings. Diabetes Care 2003; 26:2670-2674.

44. Abdul-Rahim HF, Holmboe-Ottesen G, Stene LC,Husseini A, Giacaman R, Jervell J, Bjertness E.Obe-sity in a rural and an urban Palestinian West Bank population.Int J ObesRelatMetabDisord2003; 27(1): 140-146. 